\title{
A comparison study of age- and length-structured yield-per-recruit models
}

\author{
Ir Yong Chen
}

NSW Fisheries Research Institute, PO Box 2, Cronulla, NSW, Australia 2230.

Iresent address: Chairs in Fïsheries Conservation, Fïsheries and Marine Institute, Memorial University of Nenufoundland, St.John's, Newfoundland, Canada A IC 5R3. E-mail: ychen@caribou.ifmt.nf.ca

Received October 23, 1996; accepted September 8, 1997.

Chen Y. Aquat. Living Resour., 1997, 10, 271-280.

Abstract

Résumé
Yield-per-recruit models are often used to provide management guidance for the efficient use of a fish cohort and to estimate the biological reference points, such as $F_{0.1}$ or $F_{\mathrm{MAx}}$. Although model parameters are usually age-specific, these parameters are thought to be more likely related to length than age. In this study, age- and length-structured models are compared in calculating yield per recruit, $F_{0.1}$, and $F_{\mathrm{MAx}}$ at which the yield per recruit is maximized. Using a Monte Carlo simulation approach, I also compare differences in effects of uncertainties of the model parameters on yield-per-recruit analysis and estimation of $F_{0.1}$ and $F_{\text {MAX }}$ using age- and length-structured models. This study shows that differences are small in estimating yield per recruit, $F_{0,1}$ and $F_{\mathrm{MAX}}$ using two types of models when there are no error variances in the model parameters. However, such differences increase with the uncertainties of the model parameters. The yieldper recruit, $F_{0.1}$, and $F_{\text {Max }}$ estimated using the age-structured model tend to have smaller values and variations compared with those estimated using the length-structured model. This study indicates that although the length-structured model can better incorporate the information observed from fisheries, age-structured yield-per-recruit model can provide estimates of yield per recruit, $F_{0.1}$, and $F_{\text {MAx }}$ more precisely and more conservatively, and thus is preferred from the conservation viewpoint in fisheries management.

Keywords: Fishery management, yield, mathematical models, stock assessment.

Une étude comparative entre deux modèles de rendements par recrue structurés en âge et en taille.

Les modèles de rendement par recrue sont communément utilisés pour orienter la gestion et pour estimer les points de référence biologique, $F_{0,1}$ ou $F_{\mathrm{MAX}}$. Bien que ces modèles soient habituellement structurés en âge, leurs paramètres sont plus directement liés à la taille qu'à l'âge. Dans cette étude, un modèle classique de rendement par recrue structuré en âge est modifié afin d'obtenir un modèle structuré en taille qui utilise des données basées sur les tailles, disponibles dans les statistiques de pêche. Ces modèles structurés en âge et en taille sont comparés en regard des valeurs de rendement par recrue et de mortalités par pêche, $F_{0.1}$, et $F_{\text {MAX }}$ qu'ils permettent d'estimer. En utilisant une approche par simulation de Monte Carlo, je compare aussi les deux types de modèles du point de vue des effets sur l'analyse des rendements par recrue et l'estimation de $F_{0,1}$, et $F_{\text {MAX }}$. Cette étude montre que les estimations des rendements par recrue de $F_{0.1}$, et $F_{\text {Max }}$ au moyen des deux types de modèles sont peu différentes quand on néglige la variance d'estimation des paramètres du modèle. Cependant, les différences augmentent avec l'incertitude sur les paramètres de ces modèles. Les estimations du rendement par recrue, $F_{0,1}$, et $F_{\mathrm{MAX}}$, en utilisant le modèle structuré en âge tendent à avoir des variations plus faibles que celles obtenues à partir du modèle structuré en taille. Bien que le modèle structuré en taille incorpore plus directement les informations provenant des pêches, cette étude comparative suggère que le modèle de rendement par recrue structuré en âge donne des estimations de rendement par recrue, de $F_{0,1}$, et $F_{\mathrm{MAX}}$ plus précises et plus précautionneuses, et qu'il est donc préférable du point de vue des critères biologiques de la gestion de la pêche.

Mots-clés: Pêches, rendement, modèles mathématiques, estimation de stocks. 


\section{INTRODUCTION}

Yield-per-recruit models are often used to determine management parameters such as the net mesh size which optimizes yield per recruit for a given fishing rate, the fishing rate that optimizes yield per recruit for a given net size (e.g. Ricker, 1975; Pikitch, 1987; Ehrhardt and Die, 1988). Such an analysis can provide management guidance for the efficient use of a fish cohort. Yield-per-recruit models are also frequently used to determine an important biological reference parameter $F_{0,1}$, a fishing mortality rate at which the rate of increase in yield per recruit is $10 \%$ of that when $F=0$ (Deriso, 1987; Hilborn and Walters, 1992). This parameter has been used in managing many fisheries in the world (Hilborn and Walters, 1992). For a single species yield-per-recruit analysis, no information about recruitment is required.

The Thompson-Bell, Beverton-Holt, and Ricker models are commonly used in yield-per-recruit analyses (Ricker, 1975). More recently, discrete models, analogous to the Thompson-Bell yield-per-recruit model, that incorporate age-specific gear selectivity and are developed from the catch equation and recursive exponential survival function are often used for a yield-per-recruit analysis (Murawski, 1984; Pikitch, 1987) and the determination of $F_{0.1}$ (Deriso, 1987; Punt and Butterworth, 1993). This type of model requires information that falls into the following three groups: (1) growth function that relates age and weight of fish; (2) mortality parameters including natural and fishing mortality rates; and (3) selectivity of fishing gears to fish of different sizes.

The parameters used in yield-per-recruit models are usually taken to be age dependent in a yield-per-recruit analysis, for example age-specific fishing selectivity coefficients, age at recruitment, and weight at age (Ricker, 1975). Some of these parameters, however, are more likely to be length-dependent than age-dependent (Pauly and Morgan, 1987; Isaac, 1990; Hilborn and Walters, 1992). In practice, these parameters are often derived as length-dependent in the original study, and then transferred to the age-specific parameters for the yield-per-recruit analysis using a growth function defined for the fish population (e.g. von Bertalanffy growth function; Pikitch, 1987).

The idea of length-based yield-per-recruit analyses is not new (Jones, 1980; Pauly and Morgan, 1987). The length-structured models can be obtained by re-parameterizing the usual age-structured yield-per-recruit model in a way which tends to be closer to the processes which determine the yield. This translation is not merely a mathematical artifice, because the resulting model can use data in the length-based form directly observed in fisheries. The usual age-structured model steps through time in equal discrete steps so that in early stages of growth, fish of several different sizes may be lumped together, resulting in potential inaccu- racies. In later growth stages, as fish approach their maximum length, the age-structured model may differentiate among fish of very similar size in a way which is somewhat artificial, given the length-structured processes being modelled (Chen and Gordon, 1997).

Given the above argument, it seems more reasonable to use a length-structured yield-per-recruit model in yield-per-recruit analysis. However, before affirming this conclusion, a quantitative comparison study is necessary to evaluate differences between age-structured yield-per-recruit models that are commonly used in practice and length-structured yield-per-recruit models that seem more reasonable in incorporating information observed in fisheries.

In this study, using the data simulated based on a flatfish fishery, I compared differences in calculating yield per recruit using length- and age-structured yieldper-recruit models. The differences were also evaluated when parameters are subject to error variances using a Monte Carlo simulation approach. Two biological reference points $F_{0.1}$ and $F_{\mathrm{M} \Lambda \mathrm{X}}$ (i.e. fishing mortality rate at which yield per recruit attains maxima) were calculated using both length- and age-structured yieldper-recruit models. Differences in these parameters estimated from two types of models were evaluated.

\section{Age-structured yield-per-recruit model}

The commonly used discrete yield-per-recruit model can be written as:

$$
Y=\sum_{t=t_{R}} C_{t} W_{t}\left(1-D_{t}\right)
$$

where $Y$ is the attained yield, $t_{R}$ is the age of entry into the fishery, and $t_{1}$ is the maximum age of fish that still contribute to the fishery. $W_{t}$ is the weight of fish at age $t$. It is commonly calculated as $W_{t}=a L_{t}^{b}$, where $a$ and $b$ are two parameters to be estimated. $L_{t}$ is often related to age through a growth function. In many studies, the relationship between length and age is described by the von Bertalanffy growth function. $D_{t}$ is the proportion of fish caught at age $t$ that are discarded at sea. Given mortality rates and selectivity coefficients, catch-atage $C_{t}$ can be calculated from the catch equation as:

$$
C_{t}=N_{t} \frac{S_{t}}{S_{t} F+M}\left(1-e^{-S_{t} F-M}\right)
$$

where $S_{t}$ is the selectivity coefficient for fish of age $t, F$ is the fishing mortality for fully recruited fish, $M$ is the natural mortality rate, and $N_{t}$ is the number of fish still alive at the beginning of age $t$. For simplicity, both $F$ and $M$ are assumed to be constant over time in this 
study. The relationship between recruit $R$ (i.e. number of fish at the beginning of age $t_{R}$ ) and $N_{t}$ is given by

$$
N_{t}=R e^{-\sum_{j=t_{R}}\left(S_{j} F+M\right)}
$$

Thus, the attained yield per recruit can be calculated as:

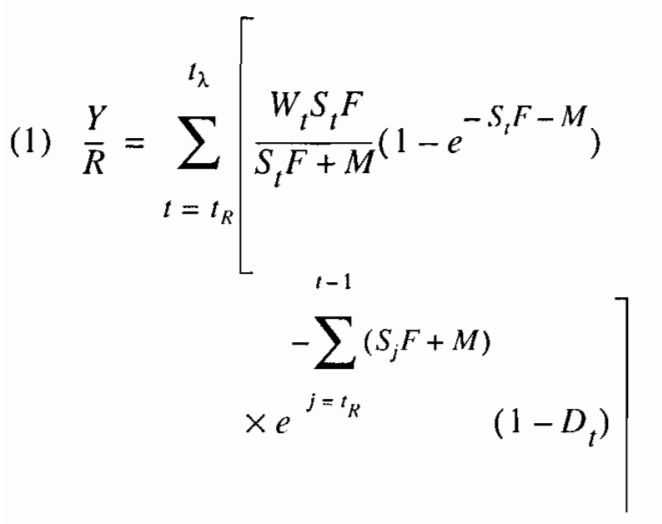

\section{Length-structured yield-per-recruit model}

Assume that the length interval between length at recruitment $L_{R}$ and maximum length of fish that still contribute to the fishery $L_{\lambda}$ can be divided into $n$ segments, $j=1, \ldots, n$. Thus, $L_{1}$ and $L_{n+1}$ correspond to $L_{R}$ and $L_{\lambda}$, respectively. The width of each divided length class need not necessarily be the same. Let the width of length class $j$ be $d_{j}$. Thus $d_{j}=L_{j+1}-L_{j}$. The time that a fish takes to grow from $L_{j}$ to $L_{j+1}, D T_{j}$, can be estimated from a growth function that describes the relationship between fish age and length. In this study, fish length-age data are assumed to be modelled by the von Bertalanffy growth function (Ricker, 1975). Thus, $D T_{j}$ can be estimated as:

$$
\Delta T_{j}=\frac{1}{K} \ln \frac{L_{\infty}-L_{j}}{L_{\infty}-L_{j}-d_{j}}
$$

$K$ and $L_{\infty}$ are parameters in the growth function.

The catch of fish in the length interval $j, C_{j}$, can be calculated using the catch equation as

$$
C_{j}=N_{j} \frac{S_{j} F}{S_{j} F+M}\left[1-e^{-\left(S_{t} F+M\right) \Delta T_{j}}\right]
$$

$$
-\sum\left(S_{k} F+M\right) \Delta T_{k}
$$

where $N_{j}=R e^{k=1}$
Similar to age-structured yield-per-recruit model, the length-structured yield-per-recruit model can be written as:

$$
\text { (2) } \left.\begin{array}{rl}
\frac{Y}{R}=\sum_{j=1}^{n} \mid \frac{W_{j} S_{j} F}{S_{j} F+M}\left(1-e^{-\left(S_{t} F+M\right) \Delta T_{j}}\right) \\
\\
\times e^{-\sum_{k=1}^{j-1}\left(S_{k} F+M\right) \Delta T_{k}} \quad\left(1-D_{j}\right)
\end{array}\right]
$$

where $W_{j}$ can be calculated from weight-length relationship, and $D_{j}$ is the proportion of caught fish in length interval $j$ that are discarded at sea. The relationship between length and its corresponding selectivity coefficient $S_{j}$ can be modelled by an exponential-logistic function (Thompson and Bakkala, 1990; Thompson, 1994) or simply a logistic function for fishing gears like trawls (Punt and Japp, 1993).

Fishing gear selectivity coefficient is the fraction of fish of a certain size retained by the gear. It is not a direct multiplier of an instantaneous rate. However, Murawski (1984) found that the product of $F$ and fishing gear selectivity coefficient is a good estimate of size-specific instantaneous fishing mortality rate. Following Pikitch (1987), I use the size-specific fishing gear selectivity observed in the fishery to approximate $S_{t}$ in equation (1) or $S_{j}$ in equation (2).

Because many fishery biological processes are more likely to be related to length, rather than age, the above length-structured yield-per-recruit model can be easily modified to incorporate other parameters that are used to describe the fishery. The price of fish is likely to be more directly related to length than age. A revenueper-recruit model can be derived by incorporating a length-dependent price schedule.

\section{A comparison study between age- and length- structured models}

A comparison study was conducted to evaluate quantitative differences in calculating yield per recruit, $F_{0.1}$, and $F_{\text {MAX }}$ using length- and age-structured yieldper-recruit models. The comparison study was done based on data simulated according to female Petrale sole (Eopsetta jordani) in the Oregon flatfish fishery described by Pikitch (1987). Values of the parameters including the von Bertalanffy growth parameters, length-weight parameters, and mortality rates used in this study are given in Table 1 .

The proportion of female Petrale sole retained by fishing gears at a given length was given by Pikitch (1987) (Fig. 1). This relationship between the retaining 
Table 1. - Parameters and their crrors used in the simulation study. Data are from Pikitch (1987)

\begin{tabular}{|c|c|c|c|c|}
\hline \multirow[b]{2}{*}{ Parameter } & \multirow[b]{2}{*}{$\begin{array}{l}\text { Nominal } \\
\text { value }\end{array}$} & \multicolumn{3}{|c|}{ Errors used in stochastic simulation } \\
\hline & & I & II & III \\
\hline \multicolumn{5}{|c|}{ von Bertalanffy growth parameters } \\
\hline$I_{\infty}$ & 54.4 & n.a. & n.a. & n.a. \\
\hline$K$ & 0.212 & n.a. & n.a. & n.a. \\
\hline$t_{11}$ & -1.82 & n.a. & n.a. & n.a. \\
\hline${ }^{1} \sigma_{\varepsilon}$ & () & 0.1 & 0.15 & 0.20 \\
\hline \multicolumn{5}{|c|}{ I ength-wcight relationship } \\
\hline a & $0.0)(3$ & n.a. & n.a. & n.a. \\
\hline$b$ & 3.281 & n.a. & na. & n.a. \\
\hline${ }^{2} \sigma_{\hat{o}}$ & () & 0.05 & 0.10 & 0.20 \\
\hline \multicolumn{5}{|l|}{ Mortality } \\
\hline$M$ & 0.20 & 0.1 & 0.3 & 0.3 \\
\hline$F$ & 0.43 & 0.1 & 0.1 & 0.1 \\
\hline \multicolumn{5}{|l|}{ Selectivity } \\
\hline$m$ & 0.668 & 0.05 & 0.05 & 0.05 \\
\hline$L 50$ & $26.60)$ & 0.05 & 0.05 & 0.05 \\
\hline \multicolumn{5}{|l|}{ Discard } \\
\hline$d \mathrm{l}$ & 0.317 & 0.0 .5 & 0.05 & 0.05 \\
\hline$d 50$ & 34.10 & 0.05 & 0.05 & 0.05 \\
\hline
\end{tabular}

proportion and the corresponding length of the fish was modelled by a two-parameter logistic model written as:

(3) $P_{j}=\frac{1}{1+e^{-m\left(L_{j}-L 50\right)}}$

where $L_{j}$ is the length of fish and $P_{j}$ is the proportion of fish at length $L_{j}$ retained by fishing gear. The $m$ and L50 are two parameters to be estimated. The former describes the rate of $P_{j}$ increasing from 0 to 1 with increased length and the latter is the length at which $50 \%$ of fish are retained by gear. The nonlinear least squares method was used to estimate $m$ and $L 50$ (Fig. 1). The estimated equation between the gear selectivity and fish length was used to approximate $S_{j}$ in Equation (2). By replacing $L_{i}$ in equation (3) with the von Bertalanffy growth function, age-specific fishing gear selectivity was calculated which was used to approximate $S_{t}$ in equation (1).

In this fishery, discarding at sea is observed. The probability of a lish being discarded was determined by its length (Fig. 2; Pikitch, 1987). The relationship between the probability of fish being discarded and

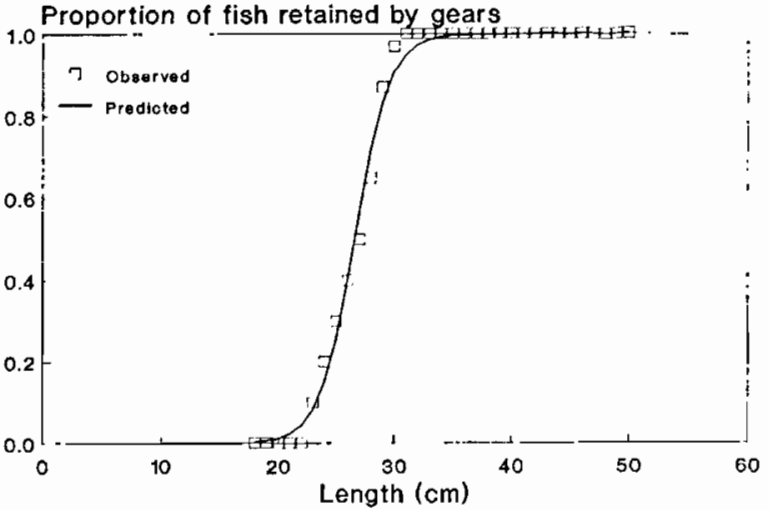

Figure 1. - Length-dependent selectivity of fishing gears with mesh size of $140 \mathrm{~mm}$ for fembale Petrale sole in an Oregon flatfish fishery. Data are from Pikitch (1987).

length was also modelled by a two-parameter logistic model written as:

(4) $D_{j}=\frac{1}{1+e^{d\left(L_{j}-d 50\right)}}$

where $D_{j}$ is the proportion of fish at length $L_{i}$ discarded. The $\mathrm{d}$ and $\mathrm{d} 50$, two parameters to be estimated. describe the $D_{j}$ values decreasing from 1 to 0 with increased length and length at which $50 \%$ of fish are discarded, respectively. The nonlinear least squares method was used to estimate $d$ and $d 50$ (Fig. 2). By replacing $L_{j}$ in Equation (4) with a growth function relating $L_{j}$ to age (i.e. von Bertalanffy growth function), age-specific discarding rate was calculated which was then used in equation (1).

The derivative of $Y / R$ with respect to fishing mortality, $\partial(Y / R) / \partial F$, was calculated. The $F_{0.1}$ was calculated iteratively from the following equation:

$$
\left.\frac{\partial(Y / R)}{\partial F}\right|_{F=F_{0.1}}=\left.0.1 \frac{\partial(Y / R)}{\partial F}\right|_{F=0}
$$

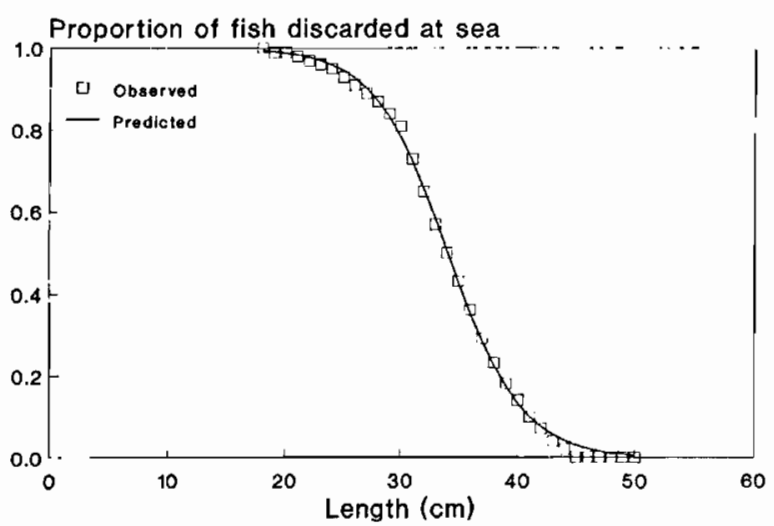

Figure 2. - Length-dependent proportion of Petrale sole discarding at sea in an Oregon flatfish fishery. Data are from Pikitch (1987).

Aquat. Living Ressur., Vol. 10. n’5 - 1997 
By equating $\partial(Y / R) / \partial F$ to 0 , fishing mortality at which yicld per recruit attains maximum value, $F_{\mathrm{MAX}}$, was calculated.

For the purpose of analysis, the nominal solution is defined as the model simulation resulting from the nominal set of parameter values. Given uncertainties associated with the model parameters, the determinislic solution represents only one possible solution to the model. The impacts of uncertainties associated with the model parameters on the evaluation of differences in estimating yield per recruit, $F_{0.1}$, and $F_{\mathrm{MAX}}$ using length- and age-structured yield-per-recruit models were determined by a Monte Carlo simulation approach.

Two approaches were used to simulate model parameters for a given level of their uncertainties. The first one is to simulate model parameters independently. This approach was used to simulate the parameters that are not highly correlated with each other. In this study, these include parameters describing sizespecific gear selectivity and proportion of fish that are discarding because correlations between $m$ and $L 50$ in equation (3) and between $d$ and $d 50$ in equation (4) were found to be small $(-0.2<r<0.2)$. Errors of these parameters were assumed to follow log-normal distribution, i.e.:

$$
B_{i}=x e^{u, Z_{i}}
$$

where $x$ is the nominal value of a parameter defined in Table $1, B_{i}$ is the simulated parameter value in the $i^{\text {th }}$ simulation run, $u_{x}$ is the standard deviation of the log crror associated with the parameter $x$, and $Z_{i}$ follows the standard normal distribution $N(0,1)$. The values of $u_{x}$ for parameters $m, L 50, d$, and $d 50$ are defined in Table 1 for 3 sets of simulation data. However, these values were determined somewhat arbitrally to facilitate the simulation study.

The second approach in simulating model parameters is to simulate parameters that are highly correlated to each other simultaneously. High correlations are usually found among parameters $L_{\infty}, K$, and $t_{0}$ in von Bertalanffy growth function and between two parameters $(a$ and $b)$ that describe length-weight relationship. Two methods were considered to simulate these parameters. One is to simulate parameters from a given multivariate normal distribution defined by a vector of means and variance-covariance matrix of the parameters (see page 316 for the algorithm; Bard, 1974). A problem associated with this approach is that it is likely that a large number of simulated parameters may have values that are biologically unreasonable. Boundaries can be pre-set to retain the simulated parameters that have reasonable values, but discard those having unreasonable values. However, when errors associated with parameters are large, a substantially large number of simulated parameters are likely to be discarded, leaving this approach inappropriate. The second method is to use the normial parameter values to calculate the "true" values of the dependent variable for the given values of
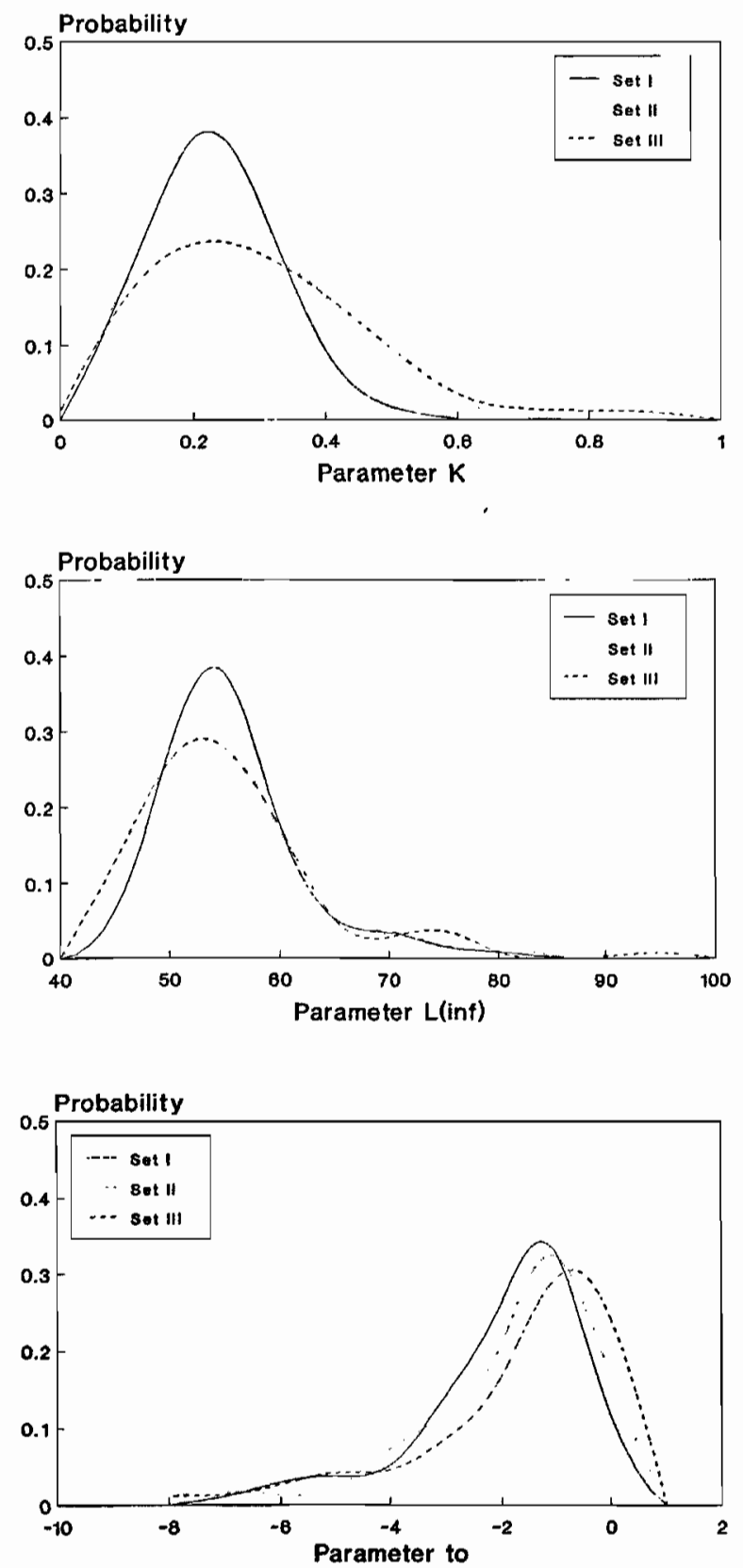

Figure 3. - The probability distribution of three parameters in von Bertalanffy growth function simulated based on error variances defined in Table 1.

the independent variable. By adding errors that follow certain distribution to the "true" values of the dependent variable, simulated values can be generated. An estimator can then be applied to the simulated values to estimate simulated parameters. By running this procedure many times, a distribution can be generated for the parameters. Parameters used in yield-per-recruit analysis can be randomly sampled from this generated distri- 

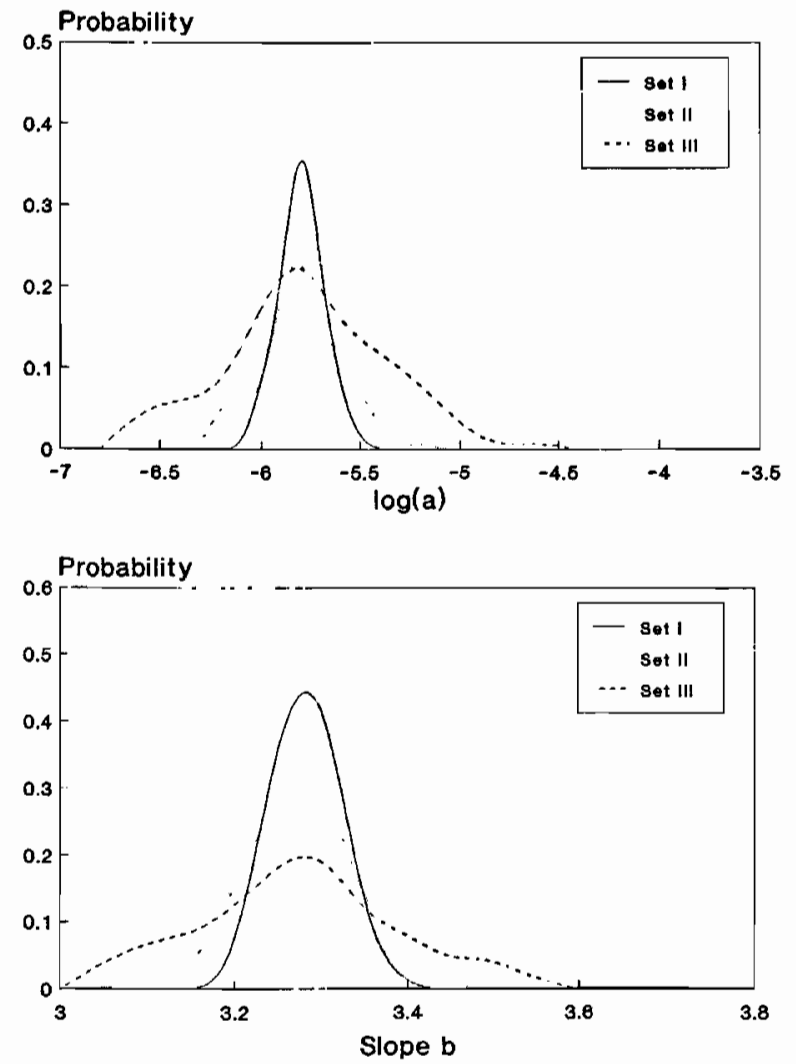

Figure 4. - The prohability distribution of two parameters in weightlength relationship simulated based on error variances defined in Table 1.

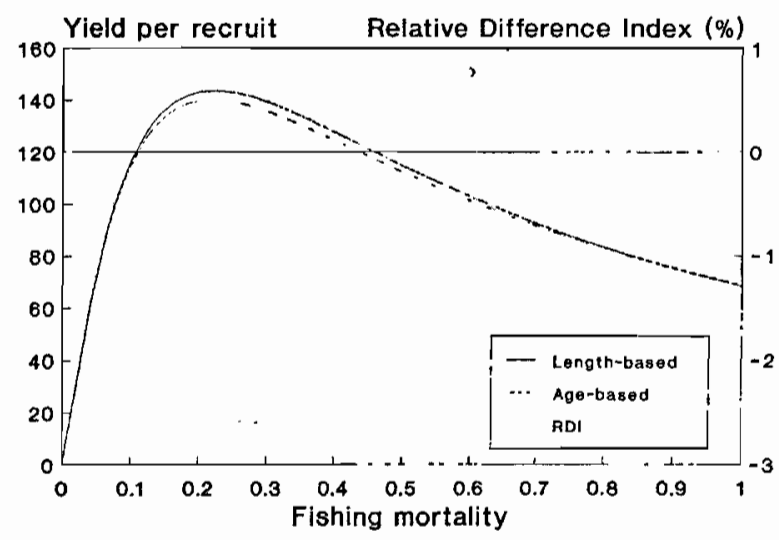

Figure 5. - Yicld per recruit estimated using age- and length-structured models and the relative difference index (RDL) at different levels of fishing mortality.

bution. More specifically, the following procedure was used to generate parameters $L_{\infty}, K$, and $t_{0}$ in this study:

(1) using the nominal values of $L_{\infty}, K$, and $t_{0}$ in Table 1 to calculate "true" length at age $L_{t}$ based on von Bertalanfly growth function;
(2) calculating simulated lengths at age $L_{t}^{\prime}$ as $L_{t}^{\prime}=L_{t} e^{\varepsilon t}$, where $\varepsilon_{t} \in N\left(0, \sigma_{\varepsilon}^{2}\right)$ and $\sigma_{\varepsilon}$ is defined in Table 1 for three sets of data;

(3) fitting von Bertalanffy growth function to these simulated lengths at age and estimating three parameters $\left(L_{\infty}, K\right.$, and $\left.t_{0}\right)$ using nonlinear least squares method (Proc nlin, SAS, 1987);

(4) repeating (2) and (3) for 1000 times to simulate 1000 sets of parameters.

The distributions of these three growth parameters are plotted in Figure 3 for the three sets of error variance $\sigma_{\varepsilon}^{2}$ delined in Table 1. Both $K$ and $L_{\infty}$ are skewed to the right while $t_{0}$ is skewed to the left. As expected, the variations in these parameters increase with error variance $\sigma_{\varepsilon}^{2}$ of simulated length at a given age (Fig. 3).

Similar approach was used to simulate parameters $a$ and $b$ that describe the weight-length relationship using the error variance defined in Table 1. The distributions of parameters $a$ and $b$ are plotted in Figure 4 . Variations in both parameters also increase with error variance in simulating weight-length data.

The model parameters of the growth function and weight-Iength relationship used in yield-per-recruit analysis were sampled randomly from the parameters simulated in the 1000 simulation runs. To ensure that the parameters generated are biologically meaningful, changes in all simulated parameters were limited to $\pm 30 \%$ of their nominal values in the simulation.

Three sets of error variance were used in the simulation study (Table 1). One hundred simulations were performed for each set of data. The distributions of estimated yicld per recruit, $F_{0.1}$, and $F_{\mathrm{MAX}}$ over 100

Table 2. - Summary of estimated yicld per recruit (YPR), $F_{0.1}$, and $F_{\text {MAX }}$ in Monte Carlo simulation study.

\begin{tabular}{llcccccc}
\hline & & \multicolumn{3}{c}{ Age-structured } & \multicolumn{3}{c}{ Length-structured } \\
\cline { 2 - 7 } Data & Statistics & YPR & $F_{0.1}$ & $F_{\text {MAX }}$ & YPR & $F_{011}$ & $F_{\text {MAX }}$ \\
\hline I & Median & 124.2 & 0.153 & 0.226 & 131.8 & 0.159 & 0.236 \\
& CV & 23.8 & 23.9 & 28.5 & 26.9 & 25.5 & 29.7 \\
& Upper 5\% & 180.3 & 0.219 & 0.331 & 187.8 & 0.231 & 0.343 \\
& Lower 5 \% & 81.4 & 0.104 & 0.113 & 69.0 & 0.107 & 0.116 \\
II & Median & 142.0 & 0.166 & 0.245 & 147.4 & 0.177 & 0.260 \\
& CV & 29.1 & 27.9 & 30.4 & 33.2 & 31.4 & 34.0 \\
& Upper 5 \% & 208.4 & 0.260 & 0.388 & 225.1 & 0.274 & 0.395 \\
& Lower 5 \% & 74.7 & 0.106 & 0.107 & 61.8 & 0.100 & 0.113 \\
& & & & & & & \\
III & Median & 1.39 .2 & 0.161 & 0.233 & 149.1 & 0.167 & 0.244 \\
& CV & 33.9 & 31.1 & 32.2 & 34.4 & 34.1 & 37.1 \\
& Upper 5 \% & 236.1 & 0.266 & 0.376 & 242.0 & 0.284 & 0.399 \\
& Iower 5\% & 75.9 & 0.107 & 0.113 & 73.7 & 0.104 & 0.114 \\
\hline
\end{tabular}



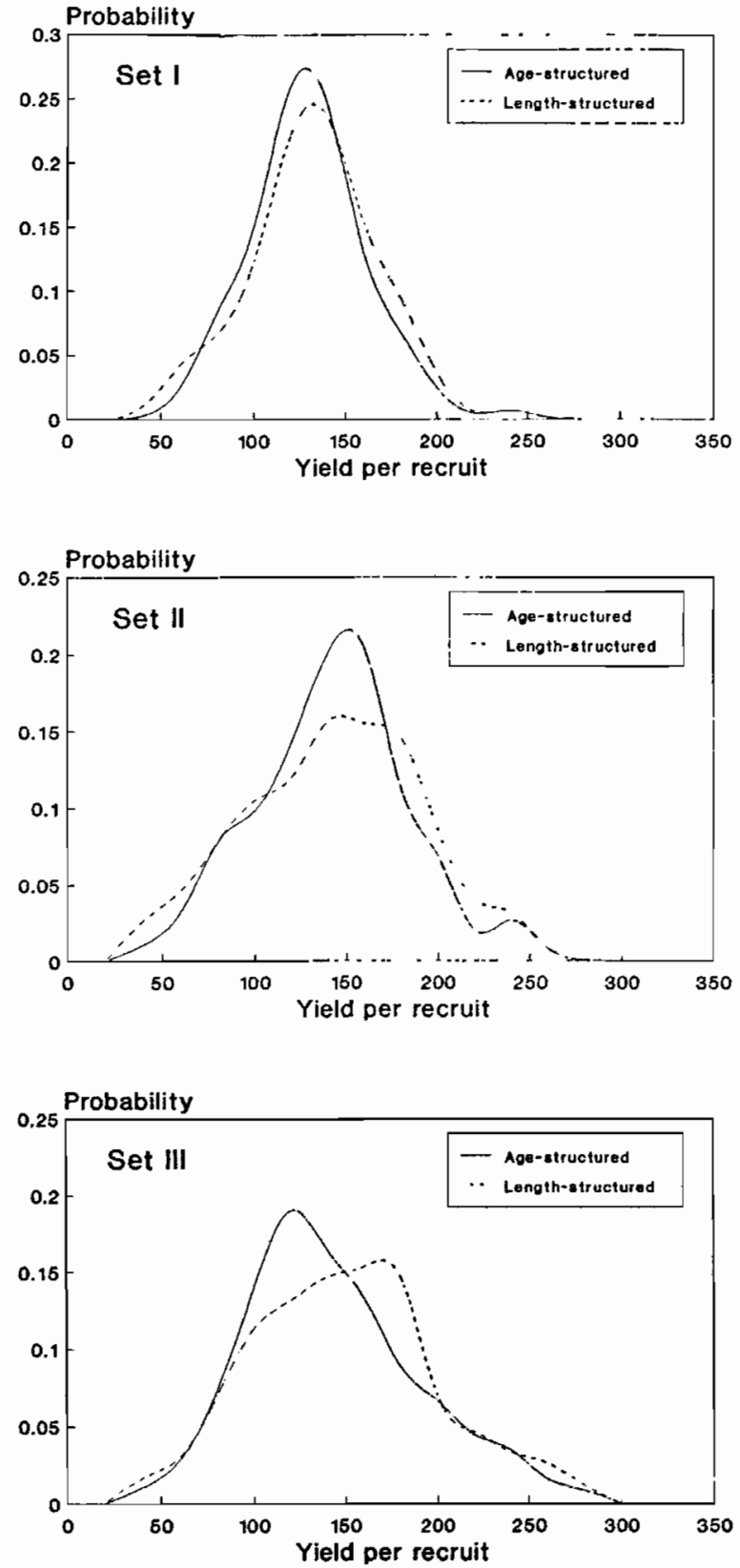

Figure 6. - The probability distribution of yield-per-recruit values estimated using age- and length-structured models for three sets of data simulated based on errors defined in Table 1.

simulation runs were calculated for both length- and age-structured yield-per-recruit analyses. A Relative Difference Index (RDI) was calculated to compare the difference in estimating yield per recruit, $F_{0.1}$, and $F_{\text {MAX }}$ using length- and age-structured yield-perrecruit models:

$$
R D I=\frac{\theta_{A}-\theta_{L}}{\theta_{L}} 100 \%
$$

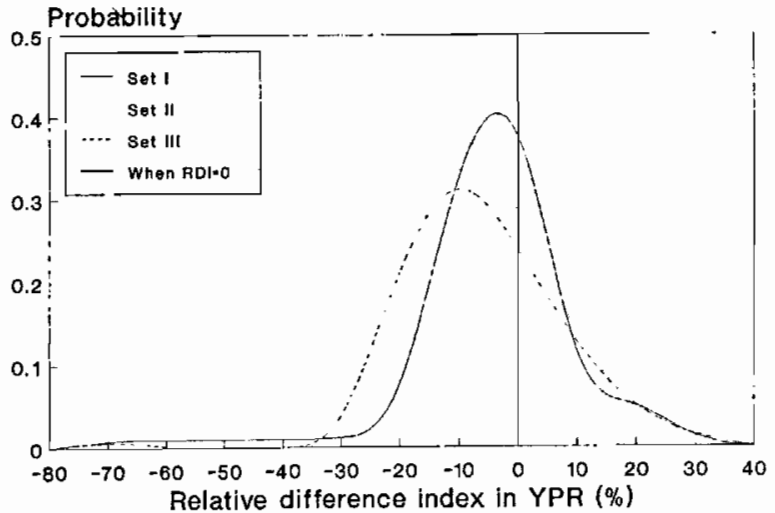

Figure 7. - The probability distribution of the Relative Difference Index (RDI) calculated for yield per recruit for three sels of data simulated based on errors defined in Table 1.

where $\theta_{A}$ and $\theta_{L}$ are statistics of interest calculated using age- and length-structured yield-per-recruit models.

\section{RESULTS}

The yield per recruit calculated using age-structured model was slightly larger than that estimated using length-structured model when $F$ was at low level (i.e. $F<0.1$ ), but smaller when $F$ was between 0.1 and 0.9 and larger again when $F$ exceeded 0.9 (Fig. 5). At the observed fishing mortality (i.e. $F=0.43$ ), the yield per recruit was $120.8(\mathrm{~g})$ for age-structured model and $123.7 \mathrm{~g}(\mathrm{~g})$ for length-structured model, yielding the RDI value of yield per recruit being $-2.3 \%$. The $F_{0.1}$ estimated from the yield per recruit was 0.143 for agestructured model and 0.148 for length-structured model. The $F_{\text {MAX }}$ was 0.214 for age-structured model and 0.218 for length-structured model. The RDI values were $-3.4 \%$ for $F_{0.1}$ and $-1.8 \%$ for $F_{\mathrm{MAX}}$.

When the model parameters were subject to uncertainties defined in Table 1, differences increased in the estimated yield-per-recruit values between length- and age-structured models (Fig. 6). Such differences increased with increased levels of uncertainties. For all three sets of simulated data, age-structured model generated yield-per-recruit estimates with tighter $90 \%$ confidence intervals and smaller coefficient of variation (CV) compared with the length-structured model (Table 2). For all data sets, the RDIs for the yield per recruit tended to have negative values in majority of the 100 simulation runs (Fig. 7), indicating that the lengthstructured model yielded a larger yield-per-recruit value than the age-structured model. For data set 1 , which had the smallest error for model parameters among three simulated data sets (Table 1), the absolute values of RDI were smaller than $10 \%$ in majority the simulation runs for the yield per recruit (Fig. 5). However, with increased levels of error in model parameters 

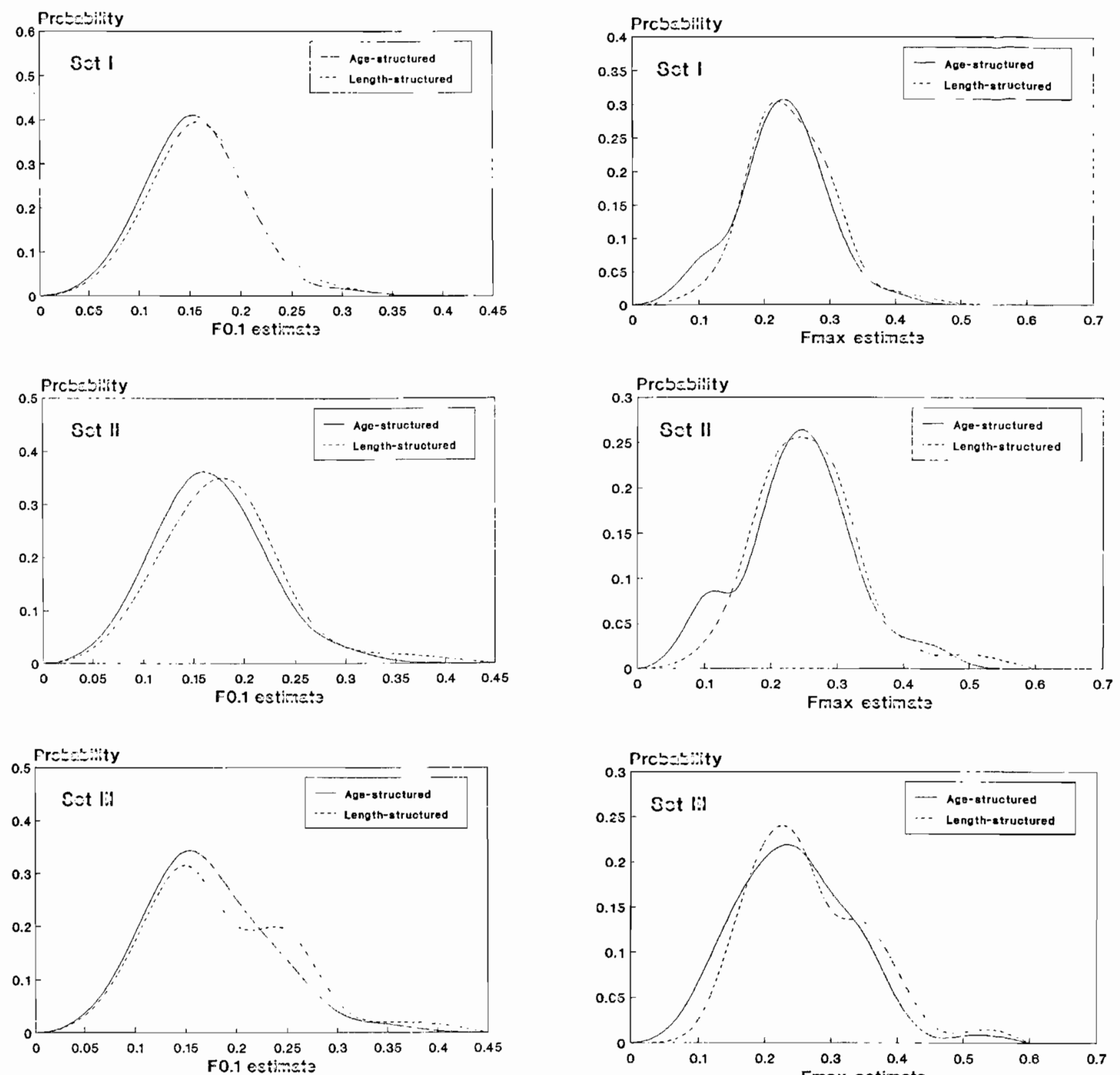

Figure 8. - The probability distribution of $F_{0.1}$ estimatcd using ageand length-structured models.

(i.e. sets II and III), the number of simulation runs with more extreme values of RDI increased greatly (Fig. 7), indicating the differences in yield per recruit calculated using length- and age-structured models increased with increased uncertainties in model parameters. The peak of the probability distribution curve of RDI for yield per recruit was located at $-5 \%,-8 \%$, and $-11 \%$ for data sets I, II, and III, respectively (Fig. 7).

Variations in the estimated $F_{0.1}$ and $F_{\text {MAX }}$ increased with uncertainties for both length- and age-structured models (Table 2). However, the age-structured model

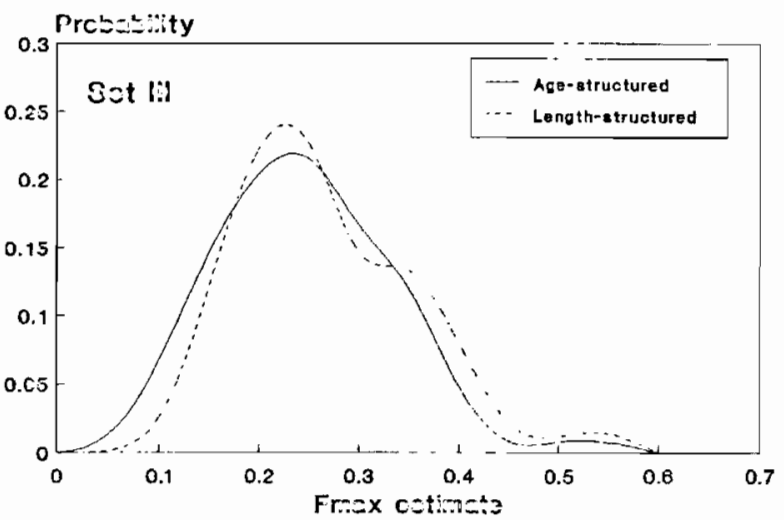

Finure 9. - The probability distribution of $F_{\text {MAX }}$ estimated using ageand length-structured models.

tended to yield $F_{0.1}$ and $F_{\text {MAX }}$ with tighter $90 \%$ confidence limits and smaller coefficients of variation than the length-structured model (Table 2). The differences in the estimated $F_{0.1}$ and $F_{\mathrm{MAX}}$ increased with the uncertainty in the model parameters (Figs. 8, 9). For all data sets, the RDIs for both $F_{0.1}$ and $F_{\mathrm{MAX}}$ had negative values in majority of the simulation runs (Fig. 10), indicating that the length-structured model yielded larger values of $F_{0.1}$ and $F_{\text {MAX }}$ than the age-structured model. The RDI values ranged from $-10 \%$ to $5 \%$ in majority of 100 simulation runs when errors in mode! 

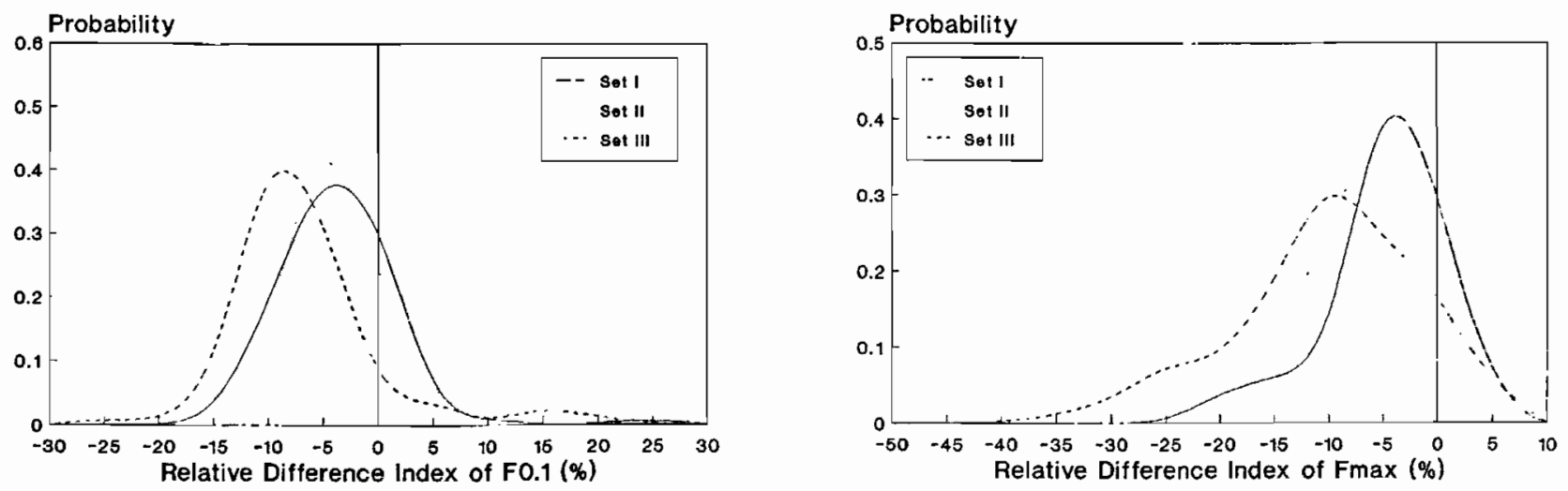

Figure 10. - The probability distribution of the Relative Difference Index (RDI) calculated for $F_{0,1}$ and $F_{\mathrm{MAX}}$.

parameters were low (i.e. set I). With increased errors in model parameters (i.e. sets II and III), there were more simulation runs for which the RDI had values beyond the ranges of $-10 \%$ to $5 \%$ (Fig. 10). Differences in $F_{0.1}$ between two models tended to be smaller than those in $F_{\text {MAX }}$ (Fig. 10).

\section{DISCUSSION}

The comparison study indicates that the differences in estimating yield per recruit, $F_{0.1}$, and $F_{\text {MAX }}$ were small using length- and age-structured models when there were no errors in model parameters. This may suggest that either length- or age-structured models can be used in a yicld-per-recruit analysis and estimating $F_{0.1}$ and $F_{\text {MAX }}$. However, $F_{0.1}$, and $F_{\text {MAX }}$ estimated from the length-structured model tended to have larger values than those estimated from the age-structured model. Thus, from conservation point of view, it may be desirable to use $F_{0.1}$ or $F_{\mathrm{MAX}}$ estimated from the age-structured model as a biological reference point.

The differences in calculating yield per recruit, $F_{0.1}$ and $F_{\mathrm{MAX}}$ using length- and age-structured models were found to increase with increased levels of uncertainty in model parameters (Figs. 7 and 10). This suggests that large differences may arise in estimating yield per recruit, $F_{0.1}$, and $F_{\mathrm{MAX}}$ by using different types of models. Thus, we have to address the question of which model should be used for estimating yield per recruit, $F_{0.1}$, and $F_{\text {MAX }}$ in the presence of uncertainties in the model parameters. In practice, many biological and fishing processes in fisheries are more closely related to length than age and parameters used in yieldper-recruit analysis are usually initially estimated as length-dependent based on data collected from fisheries (Pauly and Morgan, 1987; Isaac, 1990; Hilborn and Walters, 1992). Thus, it seems that a length-structured yield-per-recruit model is more logical than an agestructured model. However, it has been found in this study that the age-struclured model tends to have smaller values and lower variability in the estimated yield per recruit, $F_{0.1}$, and $F_{\text {MAX }}$ compared with the length-structured model. This suggests that the agestructured model can estimate these management parameters more precisely and more conservatively, and thus is more desirable in fisheries management.

$F_{0.1}$ is commonly used as a biological reference point in fisherics management because the harvest strategy based on it does not unduly reduce the spawning abundance and is rather robust to alternative stockrecruitment relationships (Deriso, 1987). For many fisheries, annual total allowable catch (TAC) is calculated in a way that ensures the resultant fishing mortality is the same as or less than $F_{0.1}$ (Hilborn and Walters, 1992). Although it is well known that $F_{0.1}$ estimated from a yield-per-recruit model is subject to uncertainty, little has been done to implement such uncertainty in calculating TAC or in evaluating the status of a fishery. The probability distributions of $F_{0,1}$ estimated from length- and age-structured models tend to be similar when the model errors are small (Fig. 8). However, the differences increase with uncertainties in the model parameters. This may result in large differences in calculating $F_{0.1}$-based TAC and its probability distribution if the probability distribution of $F_{0.1}$ is incorporated into the estimation. Because it gives a more precise estimate and a smaller value of $F_{0.1}$, agestructured model may be more desirable.

The observed fishing mortality for this flatfish fishery is 0.43 . This value is far beyond $90 \%$ confidence limits of $F_{0.1}$ and $F_{\mathrm{MAX}}$ estimated for all three sets of data using both age- and length-structured models, suggesting this fishery may be overexploited. There is no difference in status evaluations of this fishery according the whether length- of age-structured models are used.

In conclusion, although the length-structured yieldper-recruit model can better incorporate information collected from fisheries, I suggest that the age-structured yield-per-recruit model be used in estimating yield per recruit, $F_{0.1}$, and $F_{\mathrm{MAX}}$ because it can estimate these management parameters more precisely and conservatively. 


\section{Acḱnowlectgement}

I would like to thank $G$. Gordon for his help and comments. The constructive and critical comments of Dr. G. Thompson and Dr. B. Mesnil have improved this manuscript significantly.

\section{REFERENCES}

Chen Y., G.N.G. Gordon 1997. Assessing discarding at sea using a length-structured yield-per-recruil model. Fish. Res. (in press).

Chen Y., J.E. Paloheimo 1994. Estimating fish length and age at $50 \%$ maturity using a logistic type model. Aquat. Sci. 56, 206-219.

Chen Y.. G. Liggins, K.J. Graham, S.J. Kennelly 1997. Modelling length-dependent offshore distribution of redlish, Centroberyx affinis. Fish. Res. 29, 39-54.

Deriso R.B. 1987 Optimal $F_{0,1}$ criteria and their relationship to maximum sustainable yield. Can. J. Fish. Aquat. Sci. 44, (suppl.2), 339-348.

Ehrhardt N.M., D.J. Die 1988. Size-structured yield-perrecruit simulation for the Florida gill-net fishery for Spanish mackerel. Trans. Am. Fish. Soc. 117, 581-590.

Hilborn R., C.J. Walters 1992. Quantitative fisheries stock assessment: choice, dynamics, and uncertainty. Chapman and Hall, New York, $570 \mathrm{p}$.

Isaac V.J. 1990. The accuracy of some length-based methods for lish population studies. International Center for Living Aquatic Resources Management, Manila, Philippines. $81 \mathrm{p}$.

Jones R. 1981. The use of length composition data in fish stock assessments. FAO Fisheries Cir. 734, 55 p.

Murawski S.A. 1984. Mixed-species yield-per-recruit analyses accounting for technological interactions. Can. J. Fish. Aquat. Sci. 41, 897-916.
Pauly D., G.R. Morgan eds. 1987. Length-based methods in lisheries research. International Center for Living Aquatic Resources Management, Manila, Philippines, 468 p.

Pikitch E.K. 1987. Use of a mixed-species yield-per-recruit model to explore the consequences of various management policies for the Oregon flatfish fishery. Can. J. Fish. Aquat. Sci. 44 (suppl.2), 349-359.

Punt A.E., D.S. Butterworth 1993. Variance estimates for Iisheries assessment: their importance and how best to evaluate them. Risk evaluation and biological reference points for fisheries management. S.J. Smith, J.J. Hunt, D. Rivard eds. Can. J. Fish. Aquat. Sci. Spec. Publ. 120, $145-162$.

Punt A.E., D.W. Japp 1993. Stock assessment of the kingklip Genypterus capensis off South Africa. S. Afr. J. Mar. Sci. 14, 133-149.

Ricker W.E. 1975. Computation and interpretation of biological statistics of fish populations. Fish. Res. Board Can. Bull. 191,382 p.

SAS 1987. SAS/STAT guide for personal computers. Version 6, SAS Institute Inc., Cary, NC.

Thompson G.G. 1994. Confounding of gear sclectivity and the natural mortality rate in cases where the former is a nonmonotone function of age. Can. J. Fish. Aquat. Sci. 51, 2654-2664.

Thompson G.G., R.G. Bakkala 1990. Assessment of the castern Bering Sea Pacilic cod stock using a catch-at-age model and trawl survey data. Proc. Symp. Application of stock assessment techniques to Gadids. L.L. Low ed. Int. N. Pac. Fïsh. Comm. Bull. 50, 215-236 